\title{
Sintering and Foaming of Barium Silicate Glass Powder Compacts
}

\author{
Boris Agea-Blanco ${ }^{1,2}$, Stefan Reinsch ${ }^{1}$ and Ralf Müller ${ }^{*}$ \\ 'Division 5.6 "Glass", Federal Institute for Materials Research and Testing (BAM), Berlin, Germany, ${ }^{2}$ IQS School of \\ Engineering, Barcelona, Spain
}

The manufacture of sintered glasses and glass-ceramics, glass matrix composites, and glass-bounded ceramics or pastes is often affected by gas bubble formation. Against this background, we studied sintering and foaming of barium silicate glass powders used as SOFC sealants using different powder milling procedures. Sintering was measured by means of heating microscopy backed up by XPD, differential thermal analysis, vacuum hot extraction (VHE), and optical and electron microscopy. Foaming increased significantly as milling progressed. For moderately milled glass powders, subsequent storage in air could also promote foaming. Although the powder compacts were uniaxially pressed and sintered in air, the milling atmosphere significantly affected foaming. The strength of this effect increased in the order $\mathrm{Ar} \approx \mathrm{N}_{2}<$ air $<\mathrm{CO}_{2}$. Conformingly, VHE

OPEN ACCESS

Edited by:

Wolfram Höland,

Ivoclar Vivadent, Liechtenstein

Reviewed by:

Sylwester Janusz Rzoska, Institute of High Pressure Physics

(PAN), Poland

John Ballato,

Clemson University, USA

*Correspondence: Ralf Müller

ralf.mueller@bam.de

Specialty section: This article was submitted to Glass Science,

a section of the journal

Frontiers in Materials

Received: 15 June 2016 Accepted: 22 September 2016 Published: 07 October 2016

Citation:

Agea-Blanco B, Reinsch S and Müller $R$ (2016) Sintering and Foaming of Barium Silicate Glass

Powder Compacts.

Front. Mater. 3:45.

doi: 10.3389/fmats.2016.00045 studies revealed that the pores of foamed samples predominantly encapsulated $\mathrm{CO}_{2}$, even for powders milled in Ar and $\mathrm{N}_{2}$. Results of this study thus indicate that foaming is caused by carbonaceous species trapped on the glass powder surface. Foaming could be substantially reduced by milling in water and $10 \mathrm{wt} \% \mathrm{HCl}$.

Keywords: glass powder sintering, milling, foaming, degassing, SOFC

\section{INTRODUCTION}

Glass powders are widely used in fabricating sintered glass, sintered glass-ceramics, glass matrix composites, and glass-bonded ceramics or pastes when lower fabrication or processing temperatures, gas-tight seals, or complex shapes are required (Rabinovich, 1985; Schiller et al., 2008; Müller and Reinsch, 2012). One problem often addressed within this context is concurrent crystallization and sintering (Müller, 1994; German, 1996; Prado and Zanotto, 2002; Pascual and Duran, 2003; Prado et al., 2003a,b, 2008). This effect is most pronounced in sintered glass-ceramics, where a large crystal fraction is desired and rapid crystallization starts from the powder surface (Müller and Reinsch, 2012).

Many practical applications of sintered glass-ceramics, however, rely on slowly crystallizing glasses. Such glasses are, for instance, used for low temperature co-fired ceramics (Imanaka, 2005), paste glasses (Hwang et al., 2002), or SOFC sealants (Fergus, 2005; Gross et al., 2005). In the case of slow crystallization, however, another problem may arise. Due to the low glass viscosity required for joining and gas-tight sealing or obtaining a desired crystallinity, gas bubble formation, and related sample swelling ("foaming") often occur, even when organic aids are not used in powder processing.

Thus, Lucchini et al. (1983) observed an increased bubble formation with increasing glass volume fraction for sodium and calcium lead silicate glass-bonded barium hexaferrites and attributed this effect to glass volatilization. Pore formation was also observed in porcelain stoneware tiles (Leonelli et al., 2001) and lead borosilicate glass frits (Hwang et al., 2002). In the latter case, effusing oxygen 
or water, physically or chemically adsorbed to the glass powder surface during manufacturing and storage, has been supposed to be potential foaming sources. However, neither dry quenching of the molten glass nor using vacuum-dried $\mathrm{B}_{2} \mathrm{O}_{3}$ for glass melting could reduce foaming. Lara et al. (2004) observed foaming during sintering and crystallization treatments of $\mathrm{Ca}, \mathrm{Mg}$, and $\mathrm{Zn}$ alumosilicate glass powders for SOFC sealing to be most pronounced in Ca alumosilicate glass powders (up to 30\% silhouette area increase in heating microscopy experiments). The authors discussed the formation of crystals of lower density and/or gas evolution during crystallization for causing the observed foaming. More recently, foaming was mainly attributed to pore coalescence during over-firing (Lim et al., 2006), obviously assuming an encapsulated sintering atmosphere as the major foaming source. Due to the decreased sintering pressure of larger pores, less gas is forced to dissolve into the glass melt, and low viscosity allows easy bubble growth. An analogous explanation was given by Kim et al. (2007) for foaming of lead-free $\mathrm{Bi} 2 \mathrm{O} 3-\mathrm{B} 2 \mathrm{O} 3-\mathrm{SiO} 2$ solder glass powders and by Müller et al. (2009) for LTCC model glass powders. Undesired porosity was also observed during sintering ashes for porcelain tile production, which was attributed to "some boiling and trapped gas effects" (Fernandes and Ferreira, 2007).

The aim of this paper was to study the effect of glass powder milling on foaming of barium disilicate glass powder compacts. The glass powders under study have been dry-milled for different times in different atmospheres, including argon, nitrogen, air, and carbon dioxide, or wet-milled in water and $10 \mathrm{wt} \% \mathrm{HCl}$, uniaxially pressed and sintered in air. Densification and foaming was studied by means of heating microscopy backed up by $\mathrm{XRD}$, Differential thermal analysis (DTA), vacuum hot extraction (VHE), and microscopy.

\section{EXPERIMENTAL}

\section{Materials}

The present study was undertaken on a commercial barium disilicate glass with minor additions of $\mathrm{B}_{2} \mathrm{O}_{3}, \mathrm{Al}_{2} \mathrm{O}_{3}$, and $\mathrm{ZnO}$ used for SOFC sealing (Kerafol, 2010). The maximum particle size of the as-received commercial glass frit was limited to $<2 \mathrm{~mm}$ by manual crushing in a metal mortar and sieving.

In order to reach an appropriate offset particle size for the milling experiments, pre-milling was performed in air using a planetary ball mill (Fritsch Pulverisette 5, Fritsch, IdarOberstein, Germany) loaded with two 500-ml corundum jars $\left(\varnothing_{\text {in }} \approx 102 \mathrm{~mm}, h=78 \mathrm{~mm}\right.$ ). Each jar was filled with six corundum balls $(\varnothing \approx 20 \mathrm{~mm}$ ) and about $250 \mathrm{~g}$ of the glass frit. Milling was done for $15 \mathrm{~min}$ at $320 \mathrm{rpm}$ (maximum speed of supporting disk) (FRITSCH GmbH, 1987). No milling aids were used. Afterwards, a mechanical sieve (Analysette 3 PRO, Fritsch, Idar-Oberstein, Germany) was used to reduce the particle size distribution to 40-250 $\mu \mathrm{m}$ ("p0" in Table 1).

Milling was performed in a planetary ball mill equipped with two $25-\mathrm{ml}$ corundum grinding jars $\left(\varnothing_{\text {in }} \approx 33 \mathrm{~mm}, h=45 \mathrm{~mm}\right.$; Planetary micro mill Pulverisette 7, Fritsch, Idar-Oberstein, Germany) (FRITSCH GmbH, 1995). The jars were filled with four corundum balls $(\varnothing \approx 12 \mathrm{~mm})$ and $\approx 8 \mathrm{~g}$ of glass powder. In
TABLE 1 | Particle size of glass powders after different milling (p0: pre-milled).

\begin{tabular}{|c|c|c|c|c|c|c|c|}
\hline Powder & $\begin{array}{c}\text { Milling } \\
\text { time (min) }\end{array}$ & Atmosphere & Milling aid & $\begin{array}{c}D_{10} \\
(\mu \mathrm{m})\end{array}$ & $\begin{array}{c}D_{50} \\
(\mu \mathrm{m})\end{array}$ & $\begin{array}{c}D_{90} \\
(\mu \mathrm{m})\end{array}$ & $\begin{array}{c}D_{97} \\
(\mu \mathrm{m})\end{array}$ \\
\hline po & - & Air & - & 3 & 41 & 140 & 210 \\
\hline $\mathrm{p} 1$ & 5 & Air & - & 2 & 25 & 72 & 99 \\
\hline p2 & 10 & Air & - & 1 & 13 & 47 & 67 \\
\hline p3 & 15 & Air & - & 1 & 8 & 33 & 47 \\
\hline $\mathrm{p} 4$ & $2 \times 15$ & Air & - & 1 & 4 & 20 & 33 \\
\hline p5 & $3 \times 15$ & Air & - & 1 & 4 & 19 & 31 \\
\hline p6 & $4 \times 15$ & Air & - & 1 & 4 & 25 & 39 \\
\hline p7 & 15 & Air & - & 1 & 11 & 40 & 58 \\
\hline p8 & 15 & $\mathrm{CO}_{2}$ & - & 1 & 12 & 37 & 53 \\
\hline p9 & 15 & $\mathrm{~N}_{2}$ & - & 2 & 14 & 42 & 61 \\
\hline p10 & 15 & $\mathrm{Ar}$ & - & 1 & 13 & 40 & 58 \\
\hline p11 & 15 & Air & - & 1 & 11 & 73 & 108 \\
\hline p12 & $4 \times 15$ & $\mathrm{CO}_{2}$ & - & 1 & 7 & 25 & 37 \\
\hline p13 & - & Air & - & 18 & 223 & 538 & 688 \\
\hline p14 & 30 & Air & - & 1 & 6 & 32 & 62 \\
\hline p15 & 30 & Air & $\mathrm{H}_{2} \mathrm{O}$ & 1 & 5 & 15 & 22 \\
\hline p16 & 30 & Air & $10 \mathrm{wt} \% \mathrm{HCl}$ & 1 & 9 & 22 & 30 \\
\hline
\end{tabular}

order to provide a controlled milling atmosphere within these grinding jars, special ring seals were used. These rings were made of steel equipped with top and bottom silicone seals and a gas inlet capillary, which could be closed by a shuttle valve mounted on top of the rotating jar holder.

Milling progress was studied in air starting from glass powder p0 (Table 1). Glass powders were milled for 5-60 min at $766 \mathrm{rpm}$ (maximum speed of supporting disk) (FRITSCH GmbH, 1995). Milling was temporarily stopped for $30 \mathrm{~min}$ after $15 \mathrm{~min}$ of milling to prevent overheating. Starting with a large decrease of $\mathrm{D}_{50}$ during the first milling stage, the decrease in particle size progressively slowed down to level out at $\approx 4 \mu \mathrm{m}$. At 60 -min dry-milling, slightly increased $D_{90}$ and $D_{97}$ values indicate progressive particle agglomeration (p1-p6).

Milling in controlled atmospheres (p7-p10) was carried out for $15 \mathrm{~min}$ also at $766 \mathrm{rpm}$ (FRITSCH GmbH, 1995). In this case, the sealed milling jars were evacuated to $<20$ mbar and re-filled with $\mathrm{CO}_{2}, \mathrm{~N}_{2}$, and $\mathrm{Ar}$ (99.99\% purity, Air Liquide ${ }^{\mathrm{TM}}$, Germany) to $10^{5} \mathrm{~Pa}$ ( 1 bar). Evacuation and re-filling was repeated five times to minimize the amount of residual air. A liquid nitrogen trap was used to increase $\mathrm{N}_{2}$ purity. For studying the effect of powder storage in air after milling, the glass frit was crushed to $<1000 \mu \mathrm{m}$ (Jaw Crusher, Retsch BB51), sieved to 200-1000 $\mu \mathrm{m}$, and milled in air (p11) and $\mathrm{CO}_{2}(\mathrm{p} 12)$ as described.

Wet-milling started from a glass frit crushed using the same jaw-crusher: about $400 \mathrm{~g}$ of starting glass frit was repeatedly crushed using a gap width decreasing from 1000 to $200 \mu \mathrm{m}$ in $200-\mu \mathrm{m}$ steps. The last crushing step $(200 \mu \mathrm{m}$ gap width) was repeated three times ( $\mathrm{p} 13)$. Milling jars were filled with $8 \mathrm{~g}$ of this powder (p13) and milled for $30 \mathrm{~min}$ as for milling in controlled atmospheres. For powder p14, dry-milling was carried out in ambient air as a reference. Powders p15 and p16 were wet-milled in 8 -g pure water and $10 \mathrm{wt} \% \mathrm{HCl}$ (diluted from fuming $\mathrm{HCl}$ 37 wt\%, Merck, Germany), respectively. Pure water was supplied by a MilliQ ${ }^{\circledR}$ device (Merck, Germany). Wet-milled powders were dried for 2 days at $120^{\circ} \mathrm{C}$ in air before sintering. 
For the study of sintering and microstructural evolution, cylindrical powder compacts were uniaxially pressed in air at $60 \mathrm{MPa}$ (green dimensions: $\varnothing \approx 5 \mathrm{~mm}, h \approx 2 \mathrm{~mm}$, and $m \approx 0.1 \mathrm{~g}$ ) without organic aids. After milling, the powder was stored in a closed HDPE box for between 2 and 4 days before uniaxial pressing. During that time, no significant effect on sintering and foaming could be observed.

For the study of gas release from the powder surface and foamed porosity, powder compacts of cylindrical shape were uniaxially pressed at $105 \mathrm{MPa}(\varnothing \approx 5 \mathrm{~mm}, h \approx 1 \mathrm{~mm}$, and $m \approx 0.050 \mathrm{~g})$ without binders or other aids and then cut down using a scalpel to pieces of $\approx 9-10 \mathrm{mg}$. These pieces had been stored in a HDPE container before being studied by VHE.

\section{Methods}

Glass viscosity, $\eta_{\mathrm{G}}$, was measured by means of rotational concentric cylinder viscometry (VT550, Haake, Erlangen, Germany) for $\eta<10^{5} \mathrm{~Pa}$ s. The glass transition temperature $T_{\mathrm{g}}=649 \pm 3^{\circ} \mathrm{C}$ and the coefficient of thermal expansion $C_{T E} E_{25-400^{\circ} \mathrm{C}}=7.6 \times 10^{-6} \mathrm{~K}^{-1}$ were determined with a horizontal dilatometer (402 E, Netzsch, Selb, Germany; bulk glass bars, $25 \mathrm{~mm} \times 5 \mathrm{~mm} \times 5 \mathrm{~mm}$ ). The viscosity data obtained in pascal second and degree Celsius could be approximated with $\log \eta=-2.77+2644 /(T-480)$ within $\Delta$ $\log \eta \approx \pm 0.02$ accuracy.

Glass density, $\rho_{\mathrm{G}}=3.61 \mathrm{~g} / \mathrm{cm}^{3}$, was measured from glass bars by means of Archimedes' principle. A Mastersizer 2000 (Malvern Instruments, Wocestershire, U.K.) was used for particle size measurement. Particle agglomeration was minimized by dispersing $\approx 10 \mathrm{mg}$ of glass powder in a $0.003 \mathrm{M} \mathrm{Na}_{4} \mathrm{P}_{2} \mathrm{O}_{7}$ solution and subsequent ultra-sonic treatments (1-5 min). The bulk density of green and sintered specimens was obtained from their sample geometry (heating microscope) and weight.

The microstructure of powder compacts heated to selected temperatures and quenched in air was studied from polished cross-sections by means of environmental scanning electron microscopy (ESEM-FEG, Philips-XL 30, Eindhoven, Netherlands) or by an optical microscope (JENAPOL, Carl Zeiss Jena, Jena, Germany). Green powder compacts were embedded in synthetic resin for preparing cross-sections. Porosity was measured by image analysis of optical micrographs using the software Image $\mathrm{C}$ (Aquinto AG, Berlin, Germany).

Crystallization was studied by means of X-ray diffraction (Philips PW 1710, Eindhoven, Netherlands) using copper $\mathrm{K}_{\alpha}$ with $\lambda=1.5418 \AA$, in Bragg-Brentano symmetry. Data were collected for $2 \theta=5-80^{\circ}$ in steps of $0.02^{\circ} / \mathrm{s}$. Diffraction patterns were analyzed using EVA 15.1 software (Bruker-AXS, Karlsruhe, Germany) and compared to the JCPDS database (JCPDS, 2009, International Center for Diffraction Data). DTA-MS runs were performed in air at $5 \mathrm{~K} / \mathrm{min}\left(15 \mathrm{~K} / \mathrm{min}\right.$ below $\left.500^{\circ} \mathrm{C}\right)$ using $\approx 25$-mg pieces of powder compacts and Pt crucibles (TAG 24, Setaram, Caluire, France). The DTA device was coupled with a mass spectrometer (Balzers Quadstar 421, Balzers, Liechtenstein) by a heated $\left(180^{\circ} \mathrm{C}\right)$ quartz glass capillary. In this way, evolved gases were simultaneously recorded in multiple ion detection (MID) modus.

Gas release from green and sintered powder compacts was studied by means of VHE with mass spectrometer evolved gas detection (QMA4005, Balzers Instruments, Balzers, Liechtenstein). VHE analysis was performed in vacuum $\left(10^{-4}\right.$ $10^{-5}$ mbar) during heating at $20 \mathrm{~K} / \mathrm{min}$ using the MID mode (Müller et al., 2005).

Shrinkage of cylinder-shaped powder compacts during heating at $5 \mathrm{~K} / \mathrm{min}\left(<500^{\circ} \mathrm{C}, 15 \mathrm{~K} / \mathrm{min}\right)$ was examined using a heating microscope (Leitz, Wetzlar, Germany) with optical data acquisition (Hesse Prüftechnik, Osterode, Germany). Shrinkage and foaming are presented in terms of the silhouette area change, $s_{\mathrm{A}}=\Delta A / A_{0}$, where $A_{0}$ is the initial sample silhouette area of the green compact.

\section{RESULTS}

\section{Shrinkage and Foaming}

Figure 1 shows the silhouette area change, $s_{\mathrm{A}}$, for powders milled in air for different milling times (p1-p6). Sintering of the premilled powder $(\mathrm{p} 0)$ starts at $\approx 710^{\circ} \mathrm{C}$, and final densification is attained at $\approx 800^{\circ} \mathrm{C}$. With increasing milling time, i.e., with decreasing particle size, the onset and saturation stage of sintering shift to a lower temperature by $\approx 20$ and $\approx 30 \mathrm{~K}$, respectively, while the attainable maximum densification tends to increase. Beyond maximum densification, progressive foaming is evident, which is strongly promoted by prolonged milling.

Figure 2 illustrates the shrinkage and foaming behavior of glass powders milled for $15 \mathrm{~min}$ in controlled atmospheres ( $\mathrm{p} 7-$ p10). Sintering starts at $\approx 700^{\circ} \mathrm{C}$ for all powders and undergoes an initial deceleration at $\approx 760^{\circ} \mathrm{C}$. The weak shrinkage between 760 and $800^{\circ} \mathrm{C}$, best visible for the $\mathrm{N}_{2}$ milled powder, might be caused by viscous settling of the sample to the substrate under the effect of gravity. Except for milling in $\mathrm{CO}_{2}$, the shrinkage maximum occurs at $800^{\circ} \mathrm{C}$ beyond which a progressive increase of $s_{\mathrm{A}}$ due to foaming occurs. This foaming is most pronounced for milling in $\mathrm{CO}_{2}$, where it already starts at $\approx 770^{\circ} \mathrm{C}$. This finding gives clear evidence that foaming can be affected by the milling atmosphere and that $\mathrm{CO}_{2}$ is most efficient in this context.

Figure 3 shows shrinkage and foaming of glass powders milled for $15 \mathrm{~min}$ in air (p11) and stored for different exposure

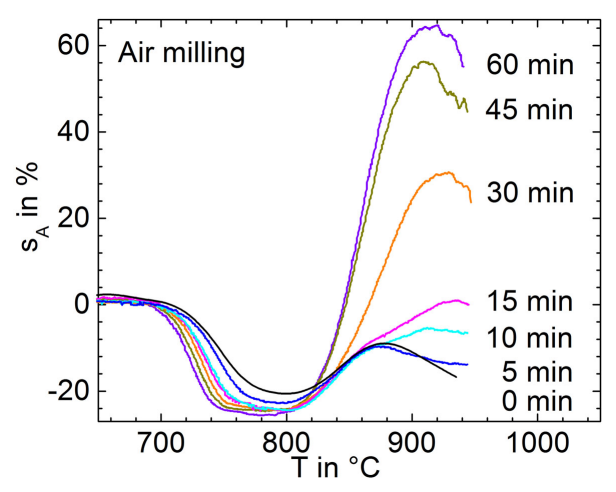

FIGURE 1 | Silhouette area change, $s_{A}$, versus temperature for glass powders milled in air during heating at $5 \mathrm{~K} / \mathrm{min}$ (p1-p6). Curve labels: milling time in minutes, 0 min indicates the pre-milled powder (p0). Adapted from Agea Blanco et al. (2015). 


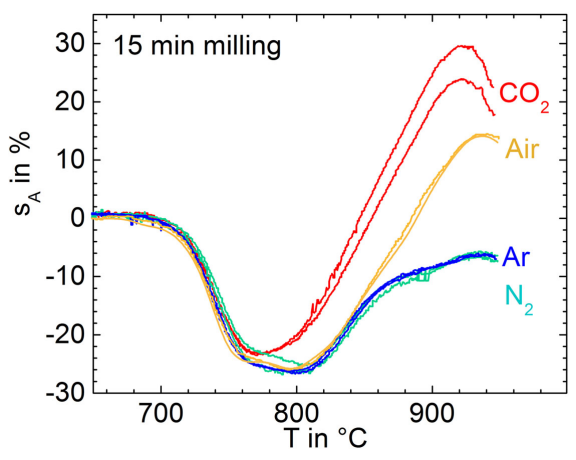

FIGURE 2 | Silhouette area change, $s_{\mathrm{A}}$, versus temperature for glass powders milled for 15 min in different atmospheres (p7-p10) during heating at $\mathbf{5} \mathbf{K} / \mathbf{m i n}$. Two experiments are shown for each condition in order to illustrate reproducibility. Adapted from Agea Blanco et al. (2015).

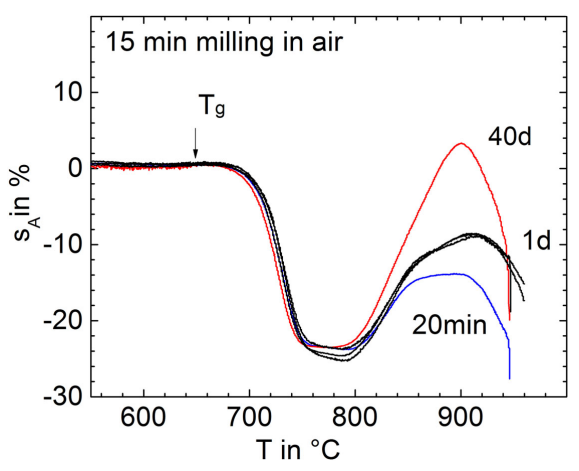

FIGURE 3 | Silhouette area change, $s_{A}$, versus temperature for glass powders milled for $15 \mathrm{~min}$ in air (p11) and subsequently stored in air for different times (curve labels) before sintering at $\mathbf{5} \mathrm{K} / \mathrm{min}$. Arrow: $T_{\mathrm{g}}=649^{\circ} \mathrm{C}$. Adapted from Agea Blanco et al. (2015).

time in air before uniaxial pressing and sintering. It is clearly seen that even short storage (1 day) substantially promoted foaming. This result indicates that gas uptake during storage in the ambient atmosphere can promote foaming.

Figure 4 illustrates the evolution of porosity during sintering for the powder milled for $15 \mathrm{~min}$ in $\mathrm{N}_{2}$. The minimum porosity occurs at $795^{\circ} \mathrm{C}$, corresponding to a maximum densification stage in Figure 2. At $875^{\circ} \mathrm{C}$, foaming is clearly detectable. The foaming maximum in Figure 2 occurred at $\approx 940^{\circ} \mathrm{C}$. Conformingly, the largest porosity in Figure $\mathbf{4}$ is seen for the cross-section of the sample heated to 950 and $1000^{\circ} \mathrm{C}$. No crystals could be observed even for the sample heated to $1000^{\circ} \mathrm{C}$. Conformingly, X-ray diffraction patterns of the powder milled for $15 \min$ in $\mathrm{N}_{2}$ (p9), heated to $940^{\circ} \mathrm{C}$, and quenched in air did not reveal the presence of crystalline phases (not shown).

Figure 5 illustrates the VHE-MS degassing behavior of green powder compacts milled for $15 \mathrm{~min}$ in different atmospheres. Below the onset of gas bubble bursting $\left(<800^{\circ} \mathrm{C}\right)$, water $(\mathrm{m} / \mathrm{e}=18)$ is the most prominent degassing species. Degassing of surfaceadsorbed water occurs between 50 and $350^{\circ} \mathrm{C}$, as previously seen for other silicate glass powders (Müller et al., 2005). This effect

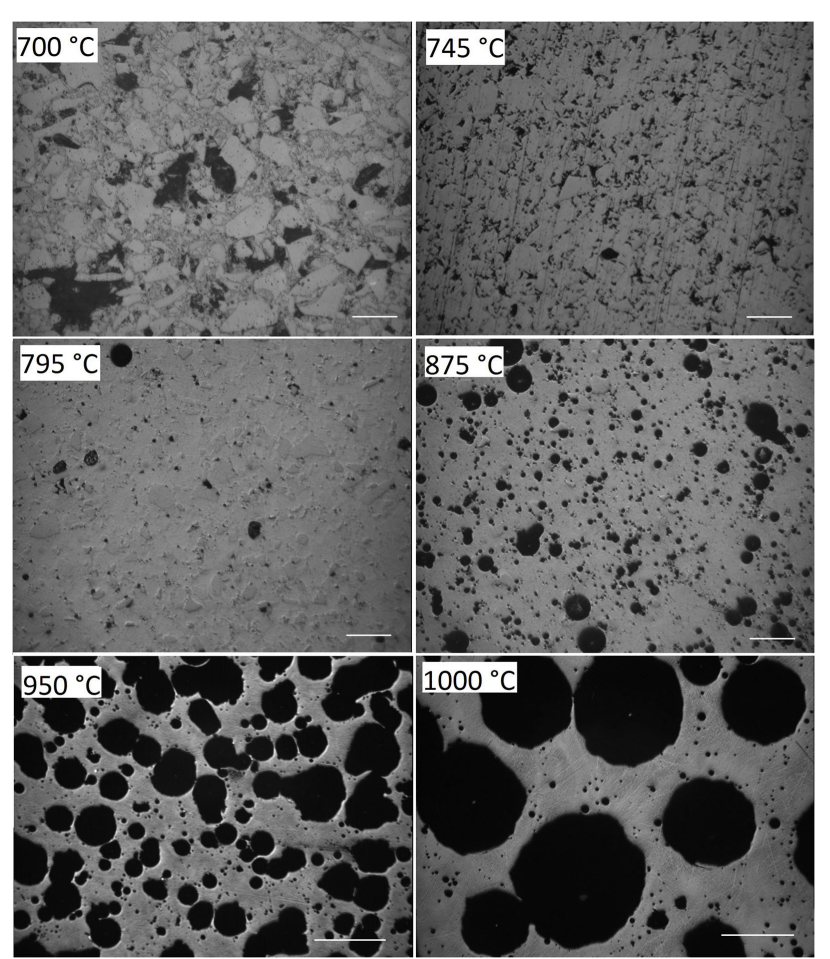

FIGURE 4 | Optical micrographs of powder compacts (15 min milling in $N_{2}, p 9$ ) heated at $5 \mathrm{~K} / \mathrm{min}$ to the temperatures indicated and quenched in air. Diamond polished cross-sections. Bars $=100 \mu \mathrm{m}$ $\left(700-875^{\circ} \mathrm{C}\right)$ and $500 \mu \mathrm{m}\left(950,1000^{\circ} \mathrm{C}\right)$. Porosity: $48 \%\left(700^{\circ} \mathrm{C}\right), 12 \%$ $\left(745^{\circ} \mathrm{C}\right), 4 \%\left(795^{\circ} \mathrm{C}\right), 20 \%\left(875^{\circ} \mathrm{C}\right), 52 \%\left(950^{\circ} \mathrm{C}\right)$, and $53 \%\left(1000^{\circ} \mathrm{C}\right)$.

causes a broad weakly structured degassing peak, which is similar for all powders. The flat degassing curve between 400 and $600^{\circ} \mathrm{C}$ mainly reflects the VHE blank value of water. Water degassing is newly accelerated when the temperature approaches $T_{\mathrm{g}}\left(649^{\circ} \mathrm{C}\right.$, arrows) and then decreases due to sintering $>700^{\circ} \mathrm{C}$, indicating that the water degassing mechanism is not exhausted but delayed by sintering. The second most intensive degassing below the onset of bubble bursting is that of $\mathrm{CO}_{2}(\mathrm{~m} / \mathrm{e}=44)$ followed by $\mathrm{CO}(m / e=28)$. The related mass number is probably not caused by $\mathrm{N}_{2}$ because of the quite different degassing characteristics of $\mathrm{N}(m / e=14)$.

During bubble bursting (spikes $>800^{\circ} \mathrm{C}$ ), $\mathrm{CO}_{2}$ is the dominant species followed by $\mathrm{C}(m / e=12)$, which is expected to occur as a fragment of $\mathrm{CO}_{2}$. This finding indicates that $\mathrm{CO}_{2}$ degassing is less exhausted below sintering than that of other volatiles. In contrast to $\mathrm{CO}_{2}, \operatorname{Ar}(m / e=40)$ and $\mathrm{N}_{2}(m / e=14)$ did not significantly contribute to bubble bursting even for the powders milled in these atmospheres. The $\mathrm{CO}_{2}$-milled powder shows the most intensive $\mathrm{CO}_{2}$ degassing during bubble bursting confirming the observed ordering of foaming activity in Figure 2. Confirmingly, integrating the $\mathrm{CO}_{2}$ ion currents $(m / e=44)$ for each of the $9-\mathrm{mg}$ samples over the temperature range of foaming $\left(800-1000^{\circ} \mathrm{C}\right)$ yields $6.0,3.8,3.1,2.9$, and $0.2 \mu \mathrm{A}$ min $\mathrm{g}^{-1}$ for milling in $\mathrm{CO}_{2}$, Air, $\mathrm{Ar}, \mathrm{N}_{2}$, and the pre-milled powder, respectively. Furthermore, bubble bursting starts at $\approx 800^{\circ} \mathrm{C}(\log \eta / \mathrm{Pas}=5.4)$ when milled 

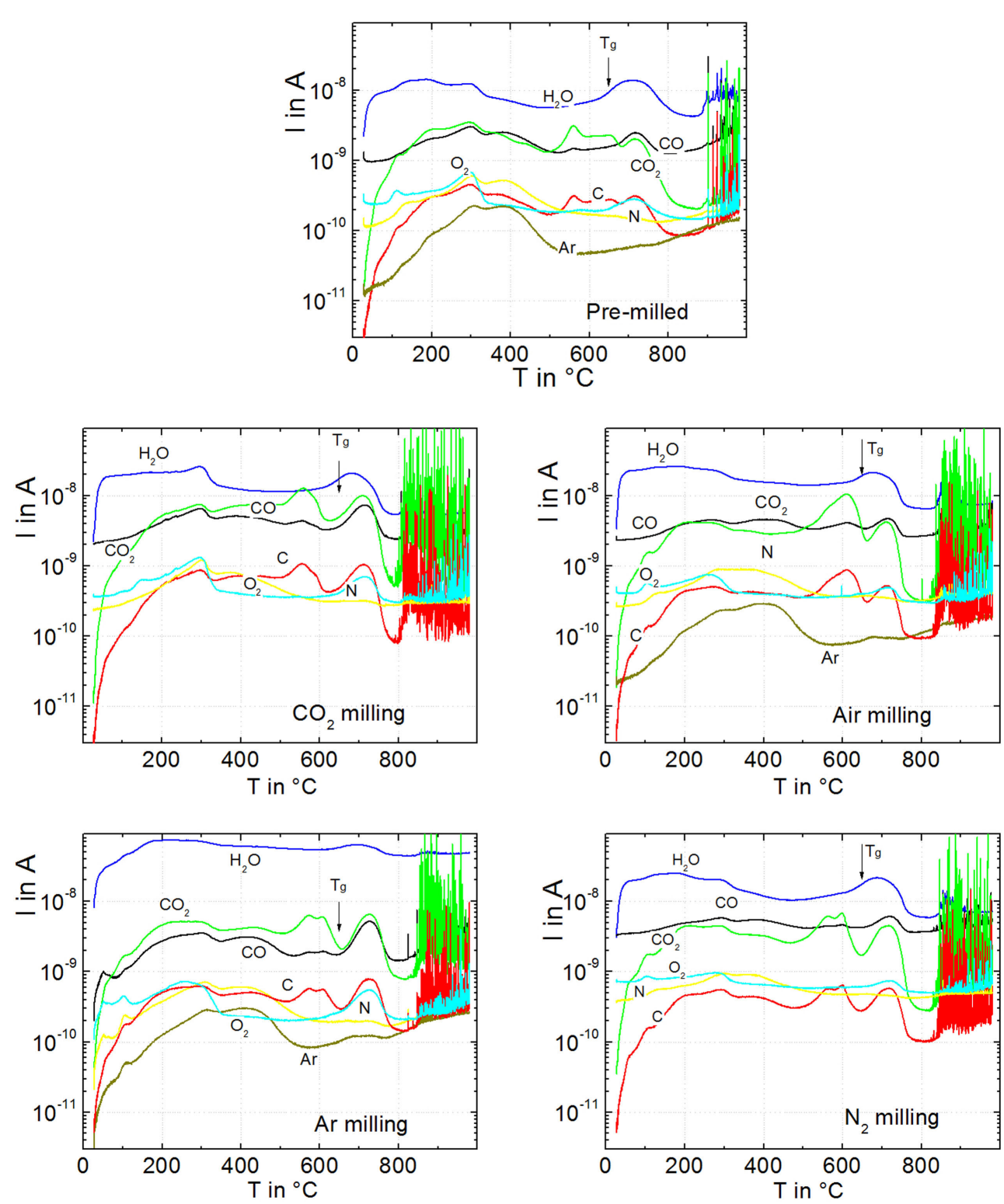

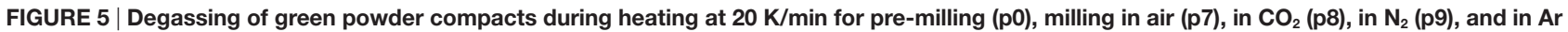
(p10). Degassing activity is presented in terms of respective ion currents, I, versus temperature, $T$. Sample mass: $\approx 9$ mg. Arrows: $T_{g}=649^{\circ} \mathrm{C}$. Adapted from Agea Blanco et al. (2015).

in $\mathrm{CO}_{2}$, while for milling in $\mathrm{Ar}, \mathrm{N}_{2}$, and air, bubble bursting starts at $\approx 840^{\circ} \mathrm{C}(\log \eta / \mathrm{Pas}=4.6)$. This effect resembles the similar trend in onset temperatures of foaming in Figure 2. The onset temperature of bubble bursting is controlled by viscosity and bubble pressure. The almost identical sintering observed among all samples in Figure $\mathbf{2}$ indicates that the milling atmosphere has a negligible effect on glass viscosity. The early onset of foaming for milling in $\mathrm{CO}_{2}$ should, therefore, mainly reflect increased bubble pressure.

Enhanced $\mathrm{CO}_{2}, \mathrm{CO}$, and $\mathrm{C}$ degassing is evident around $300^{\circ} \mathrm{C}$, at $\approx 500-650^{\circ} \mathrm{C}$, and at $\approx 650-800^{\circ} \mathrm{C}$ below the onset of foaming. Since it is obviously delayed by sintering, the latter peak at $\approx 650-800^{\circ} \mathrm{C}$ is the most likely source of foaming. It is worth noting that the onset of this degassing peak nicely correlates with the glass transition temperature (arrows in Figure 5). Similar degassing patterns were observed for the diffusion-limited release of water dissolved during glass melting at ambient pressure (Müller et al., 2005). However, it is seen from the much less intensive bubble bursting of pre-milled powders that this effect should have minor impact on the extensive bubble bursting of milled powders. Instead, because of the large effect of particle size on foaming (Figure 1), this observation might indicate diffusive degassing from the near-surface region of the powder.

Figure 6 compares $\mathrm{CO}_{2}$ degassing, silhouette area change, and DTA curves of a glass powder milled for $1 \mathrm{~h}$ in $\mathrm{CO}_{2}$ (p12). The prolonged milling time was required in order to overcome 
the lower gas detection limit of the DTA-MS device used here. Besides $\mathrm{CO}_{2}$, no other volatiles were detectable. Figure 6 gives clear evidence that $\mathrm{CO}_{2}$ is the dominant foaming source even during heating in air and ambient pressure. The broad structureless degassing peak $\left(T_{\max }\right.$ at $\left.\approx 300^{\circ} \mathrm{C}\right)$ further indicates a pronounced continuous release of $\mathrm{CO}_{2}$ during heating and that sintering only traps a rather small fraction of its initial amount. Nevertheless, this small amount obviously causes substantial foaming until the foamed sample starts to collapse at $>880^{\circ} \mathrm{C}$ via gas bubble bursting (spikes). In contrast to Figure 5, no pronounced increase of degassing activity is seen just above $T_{\mathrm{g}}$. The DTA curve reveals a weak endothermic shoulder at $T_{\mathrm{g}}$, a distinct endothermic shoulder within the temperature range of shrinkage and a broad pronounced peak nicely correlating with foaming.

Figure 7 compares sintering and foaming when milled for $30 \mathrm{~min}$ in air (p13), water (p14), and $10 \mathrm{wt} \% \mathrm{HCl}$ (p15). Sintering starts at $\approx 700^{\circ} \mathrm{C}$ in all cases. Wet-milled powders exhibit slightly increased area shrinkage, which may at least partially reflect different powder compact green densities due to possibly altered glass surface properties $\left(\rho_{0}=62,55\right.$, and $55 \%$ for $\mathrm{p} 14, \mathrm{p} 15$, and

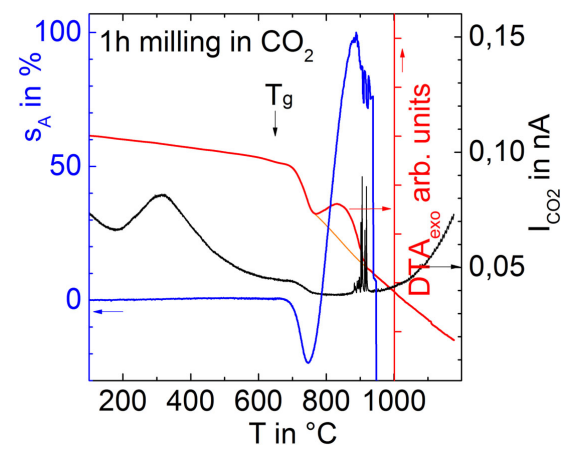

FIGURE 6 | Silhouette area change $\left(s_{\mathrm{A}}\right)$, MS degassing current for $\mathrm{CO}_{2}$ $\left(I_{\mathrm{CO}_{2}}\right)$, and DTA of a glass powder milled for $1 \mathrm{~h}$ in $\mathrm{CO}_{2}$ (p12) during heating in ambient air at $5 \mathrm{~K} / \mathrm{min}$.

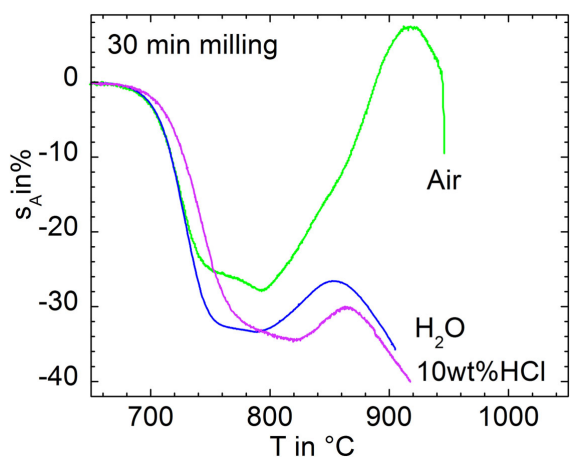

FIGURE 7 | Silhouette area change, $s_{A}$, versus temperature for $\mathbf{3 0}$ min milled in air (p14), water (p15), and $10 \mathrm{wt} \% \mathrm{HCl}$ (p16) during heating at $5 \mathrm{~K} / \mathrm{min}$. p16, respectively). Furthermore, shrinkage was slightly decelerated for the powder milled in $\mathrm{HCl}$, although its particle size does not significantly differ from powders p14 and p15 (Table 1). This effect is accompanied by a shift of the foaming onset by $30 \mathrm{~K}$ to $820^{\circ} \mathrm{C}$. Both observations hint of a possible increase of viscosity. The latter effect could be caused by increased glass viscosity (e.g., related to aqueous $\mathrm{Ba}$ dissolution from the glass surface), the presence of rigid inclusions (e.g., $\mathrm{BaCl}_{2}$ precipitates), or by both phenomena.

Most notably, however, Figure 7 gives clear evidence that foaming has been substantially reduced by means of wet-milling. Thus, foaming caused a silhouette area increase of $\Delta s_{\mathrm{A}}=35 \%$ for the 30 min dry-milled powder (p14), whereas $\Delta s_{\mathrm{A}}=7 \%$ and even $4 \%$ were evident for the powders milled in water (p15) and $\mathrm{HCl}$ (p16), respectively. Table $\mathbf{1}$ indicates that this effect is not just feigned by a deviating particle size distribution as $D_{10}$ and $D_{50}$ values are quite similar. Decreased $D_{90}$ and $D_{97}$ data for water milling may reflect a reduced agglomeration tendency.

Water- versus dry-milling experiments, similar to that presented in Figure 7, have also been conducted repeatedly using various milling materials including $\mathrm{Cr}-\mathrm{Ni}$ steel, $\mathrm{Si}_{3} \mathrm{~N}_{4}$, and WC. In all cases, a substantial reduction of foaming was observed. The use of steel milling jars in wet-milling could reduce foaming from $\Delta s_{\mathrm{A}}=48 \%$ (dry-milling) to $\Delta s_{\mathrm{A}}=9 \%$. Similar ratios $\left(\Delta s_{\mathrm{A}}=52-34 \%\right.$ versus $\left.\Delta s_{\mathrm{A}}=5-8 \%\right)$ occurred for $\mathrm{Al}_{2} \mathrm{O}_{3}, \mathrm{Si}_{3} \mathrm{~N}_{4}$, and WC. Furthermore, it was found that for milling in corundum jars and $10 \mathrm{wt} \% \mathrm{HCl}$, prolonged storage up to 12 days did not significantly influence $\Delta s_{\mathrm{A}}$, which scattered between 5 and $6 \%$ for all applied storage times.

\section{DISCUSSION}

As discussed in previous literature, different sources may contribute to foaming: gases encapsulated within the closed pore volume of the powder compact (Lim et al., 2006; Kim et al., 2007; Müller et al., 2009), gases adsorbed onto the glass powder surface (Hwang et al., 2002), glass volatilization (Lucchini et al., 1983), or effusing oxygen from the glass bulk (Hwang et al., 2002). Due to the strong effect of particle size on foaming activity (Figures 1 and 5), the latter two mechanisms should not dominate foaming in the present study.

\section{Gas Trapped in the Foaming Sample}

In order to reveal to what extent encapsulated and adsorbed gases may contribute to foaming in the present study, the amount of gas trapped in the maximal foamed sample, $n_{\mathrm{Max}}$, was estimated first. The 15-min $\mathrm{N}_{2}$-milled powder was used for this estimation as an optimum between detectable foaming and minor bubble bursting activity below the foaming maximum. Nevertheless, $n_{\text {Max }}$ can only provide a lower limit of this amount.

(i) As an initial approach for estimating $n_{\mathrm{Max}}$, the porosity, $P$, of foamed samples was measured from cross-section micrographs of powder compacts heated to different temperatures and quenched in air, by means of image analysis. Respective 


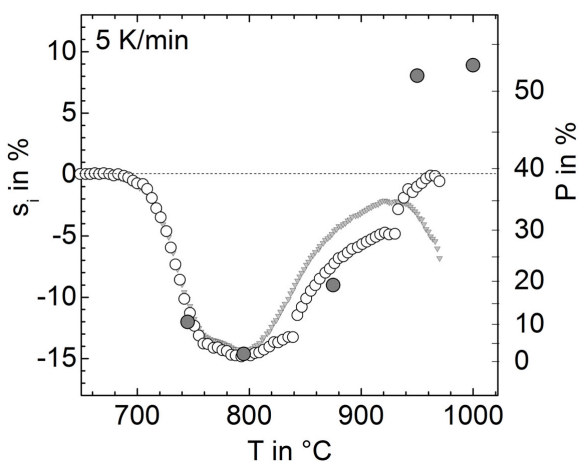

FIGURE 8 | Linear isotropic shrinkage, $s_{\mathrm{i}}$ (open circles, left ordinate) and respective porosity, $P$ (gray circles, right ordinate) versus temperature for the powder milled for $\mathbf{1 5}$ min in nitrogen (p9). For calculating $s_{i}$ from $s_{A}$, a different sample shape has been adopted: cylinder $\left(T<840^{\circ} \mathrm{C}\right)$, hemisphere $\left(840-930^{\circ} \mathrm{C}\right)$, and spherical cap $\left(930-980^{\circ} \mathrm{C}\right)$. Gray triangles: silhouette area shrinkage (see Figure 1), $s_{A}$, rescaled by $1 / 2$. Gray circles: porosity measured from cross-sectional micrographs.

values are shown in Figure $\mathbf{8}$ (right ordinate, gray circles). Maximal porosity scatters around $52 \%(0.52)$. $n_{\text {Max }}$ can be estimated from this value with Eq. 1, where $P$ is the porosity, $V$ the sample volume, $P \cdot V$ the pore volume, $R$ the ideal gas constant, $T$ the temperature, and $p$ the internal pressure:

$$
p(V \cdot P)=n_{\mathrm{Max}} R T
$$

$p$ was assumed to be $\approx 10^{5} \mathrm{~Pa}$ ( 1 bar) due to the low viscosity expected at the foaming maximum and because the majority of pore radii, $r$, were much greater than $50 \mu \mathrm{m}$. For such condition and a surface energy of $\gamma \approx 0.3 \mathrm{~J} \mathrm{~m}^{-2}$ (estimated with SciGlass 6.5 software), the Laplace pressure $P_{\mathrm{L}} \approx 2 \gamma / \mathrm{r}$ (German, 1996) should be small $\left(<0.12 \times 10^{5} \mathrm{~Pa}\right)$ and was therefore neglected. Based on $P \approx 0.52, n_{\text {Max }} \approx 16 \times 10^{-8} \mathrm{~mol}$ was found.

(ii) A more average value of $P$ can be calculated from the linear isotropic shrinkage, $s_{\mathrm{i}}=\left(\Delta V / V_{0}\right)^{-3}$, where $V_{0}$ is the initial sample volume. $s_{\mathrm{i}}$ is related to $P$ according to Eq. 2 (Winkel et al., 2012)

$$
P=1-\rho=1-\frac{\rho_{0}}{\left(1-s_{1}\right)^{3}}
$$

where $\rho$ and $\rho_{0}$ denote the relative density and the relative green density, respectively. In order to calculate $s_{\mathrm{i}}$ from the measured silhouette area change data, $s_{\mathrm{A}}$, the current sample volume, $V$, has to be inferred from the sample silhouette area, $A$. In that case, a regular sample shape must be adopted. Up to $800^{\circ} \mathrm{C}$, the sample shape could be reasonably approximated as a cylinder. Its volume is given by Eq. 3 as follows (Sieber, 1980):

$$
V_{\mathrm{C}}=\frac{\pi}{4} d^{2} h=\frac{\pi}{4 h} A^{2}
$$

where $d, h$, and $A$ (where $A=d \cdot h$ ) represents the diameter and the height of the cylinder and its silhouette area, respectively. Above $850^{\circ} \mathrm{C}$, heating microscopy data showed that samples underwent substantial rounding resembling more a hemisphere (not shown). The volume of a hemisphere can be related to its sample silhouette according to Eq. 4 (Sieber, 1980)

$$
V_{\mathrm{H}}=\frac{4 \pi}{6}\left(\frac{d}{2}\right)^{3}=\frac{4 \pi}{6}\left(\frac{2 A}{\pi}\right)^{\frac{3}{2}}
$$

where $d$ refers to the diameter of the hemisphere and $A=(1 / 8) \pi \mathrm{d}^{2}$ to its silhouette. Above $920^{\circ} \mathrm{C}$, the sample shape rather resembles a spherical cap. Its volume is given by Eq. 5 as follows (Sieber, 1980):

$$
V_{\mathrm{P}}=\frac{\pi h}{6}\left(\frac{3 d^{2}}{4}+h^{2}\right)
$$

In this case, $d$ denotes the base radius of the cap.

The linear isotropic shrinkage calculated in this way is shown in Figure 8 (open circles) in terms of $s_{\mathrm{i}}$ (left ordinate) and $P$ (right ordinate). Below $840^{\circ} \mathrm{C}, s_{\mathrm{i}}$ clearly resembles the measured silhouette area shrinkage rescaled by $1 / 2$. Above $800^{\circ} \mathrm{C}$, silhouette area shrinkage significantly deviates from $s_{\mathrm{i}}$. The discontinuities in $s_{\mathrm{i}}$ at 840 and $930^{\circ} \mathrm{C}$ represent a rough measure of the calculation errors caused by the incorrect, sample-shape assumptions. Among the large variety of error sources, the loss of rotational symmetry of the sample during foaming seems to be most important. Nevertheless, estimating $n_{\text {Max }}$ from shrinkage data indicates similar volumes of the maximal foamed sample and the green powder compact, i.e., similarity of the respective porosity $P \approx 0.39$. Thus, as a rough measure, $n_{\text {Max }} \approx 12 \times 10^{-8}$ mol could be estimated from Eq. 1 .

\section{Encapsulated Gas}

The amount of gas encapsulated within the closing porosity during sintering, $n_{\mathrm{Enc}}$, was roughly estimated assuming that porosity suddenly closes at $\rho=0.8$ (German, 1996). The number of gas moles encapsulated therein was approximated from Eq. 1, estimating $V$ from the measured sample weight $(94 \mathrm{mg})$, the relative compact density $(\rho=0.8)$ and the glass density $\left(\rho_{\mathrm{G}}=3.61 \mathrm{~g} / \mathrm{cm}^{3}\right)$. This estimation results in $n_{\text {Enc }} \approx 8 \times 10^{-8} \mathrm{~mol}$.

Comparing $n_{\mathrm{Enc}} \approx 8 \times 10^{-8} \mathrm{~mol}$ with $n_{\mathrm{Max}} \approx 12-16 \times 10^{-8} \mathrm{~mol}$ suggests that gases physically encapsulated within the porosity of sintered compacts may actually contribute to foaming. However, since mainly $\mathrm{CO}_{2}$ is released during bubble bursting and only traces of $\mathrm{N}_{2}$ and Ar were detected even for the powders milled in these atmospheres (Figure 5), the powder atmosphere must have changed after milling.

Moreover, this estimation was done for the sample milled for $15 \mathrm{~min}$ in $\mathrm{N}_{2}$. As seen from Figure 1, prolonged milling significantly increases foaming activity. Since the amount of encapsulated gas, i.e., the volume of $20 \%$ porosity, should not be affected by particle size and keeping in mind that $n_{\text {Max }}$ provides only a lower limit, this observation gives clear evidence that the encapsulated sintering atmosphere does not significantly contribute to foaming in this case. Instead, foaming seems to be clearly caused by species located at the glass powder surface. 


\section{Adsorbed Gases}

In order to check the potential effect of adsorbed gases on foaming, the respective amount of adsorbed gas, $n_{\mathrm{A}}$, was roughly estimated assuming a mono-atomic layer of nitrogen molecules remaining stable until sintering. The specific powder surface area, $a_{\mathrm{s}}=0.42 \mathrm{~m}^{2} / \mathrm{g}$, was taken from PSD analysis as the average from all $15 \mathrm{~min}$ milling experiments. The diameter of the nitrogen molecule, $d_{\mathrm{N}_{2}}$, was set at $0.34 \mathrm{~nm}$ (Doremus, 1973). The total powder surface area, $S=3.7 \times 10^{-2} \mathrm{~m}^{2}$ was then obtained from the measured sample mass, $m \approx 9.4 \times 10^{-2} \mathrm{~g}$. Assuming that one nitrogen molecule occupies an area of $\approx \pi\left(d_{N_{2}} / 2\right)^{2} \approx 0.11 \mathrm{~nm}^{2}$, $n_{\mathrm{A}} \approx 70 \times 10^{-8} \mathrm{~mol}$ of nitrogen molecules can be adsorbed onto the total sample surface area. It is interesting to note that $n_{\mathrm{A}}$ is about 10 times larger than $n_{\text {Max }}$ emphasizing the potentially strong effect of surface desorption on foaming. Taking into account that multiple physisorbed layers or multilayers grown from chemisorption and reorganization or chemical reaction processes can occur (Bhushan, 2013), this conclusion seems even more reasonable.

For physically adsorbed gases, as is expected for $\mathrm{N}_{2}$ and Ar, this conclusion however, is questionable because of low thermal stability (Bhushan, 2013). Thus, Figure 5 shows that $\mathrm{N}_{2}$ and $\mathrm{Ar}$ do not significantly contribute to foaming even for milling in these atmospheres and that the respective broad degassing peak is exhausted at around $500^{\circ} \mathrm{C}$. Low desorption temperatures are also known for $\mathrm{CO}_{2}$. Thus, complete degassing of physically adsorbed $\mathrm{CO}_{2}$ was found $<250^{\circ} \mathrm{C}$ for silica surfaces (Antonini and Hochstra, 1972) and $<120^{\circ} \mathrm{C}$ for $\eta-\mathrm{Al}_{2} \mathrm{O}_{3}$ (Morterra et al., 1977).

Much higher desorption temperatures can be expected for chemisorbed gases. Water is known to strongly interact with silicate glass surfaces. Thus, a significant concentration of 1.2 $\mathrm{OH}$ groups per square nanometer was found even after high vacuum annealing at $700^{\circ} \mathrm{C}\left(5.2 \mathrm{OH} / \mathrm{nm}^{2}\right.$ at $\left.23^{\circ} \mathrm{C}\right)$ (Dunken, 1981). Conformingly, Figure 5 shows that water is the dominant degassing species below the onset temperature of foaming at $\approx 800^{\circ} \mathrm{C}$.

Nevertheless, bubble bursting, i.e., foaming, is dominated by $\mathrm{CO}_{2}$. This gives clear evidence that $\mathrm{CO}_{2}$ adsorption results in carbonaceous species being thermally stable at least up to the temperature at which the open porosity of sintering powder compacts is closed $\left(\approx 750^{\circ} \mathrm{C}\right)$. It is reasonable to assume that the carbonaceous species, most likely carbonates, may provide sufficient thermal stability. Thus, the decomposition temperature of $\mathrm{BaCO}_{3}$ in air is found at $\approx 900^{\circ} \mathrm{C}$ (Liptay, 1976), $\mathrm{BaCO}_{3}$ species at $\mathrm{Pt} / \mathrm{BaO} / \gamma-\mathrm{Al}_{2} \mathrm{O}_{3}$ surfaces remain stable up to $500^{\circ} \mathrm{C}$ in vacuum (Epling et al., 2008), and pronounced $\mathrm{CO}_{2}$ degassing from silica glass-fiber surfaces between 500 and $700^{\circ} \mathrm{C}$ has been attributed to $\equiv \mathrm{Si}-\mathrm{O}-\mathrm{C}(\mathrm{O})-\mathrm{O}-\mathrm{Si} \equiv$ (Eremenko et al., 1991). Further, Cerruti and Morterra (2004) reported carbonate species stable up to $800^{\circ} \mathrm{C}$ at the surface of bioactive glass powders. It is also known that intensive milling of alkaline earth metasilicates can yield remarkable $\mathrm{CO}_{2}$ uptake (Kalinkin and Kalinkina, 2010 ) and that even grinding of $\mathrm{Na}_{2} \mathrm{Si}_{2} \mathrm{O}_{5}$ glass in air can cause detectable amounts of $\mathrm{NaCO}_{3}$ at the surface (Baker et al., 1995). Conclusions on the nature of the dominant carbonaceous species, however, cannot be drawn from the present study. Due to the expected small concentration $\left(\approx 60 \mathrm{ppm} \mathrm{CO}_{2}\right.$ would result from $n_{\text {Max }}=12 \times 10^{-8} \mathrm{~mol}, m_{\text {Sample }} \approx 92 \mathrm{mg}$, and $\rho_{\text {Glass }} \approx 3.61 \mathrm{~g} / \mathrm{cm}^{3}$ as discussed above for Figure 8), XRD, DTA, and ATR-FTIR studies conducted so far have not yet revealed any reliable hint of the nature of the carbonaceous species responsible for foaming found in the present study.

\section{Dissolved Gases}

The detection of these carbonaceous species might be even more complicated as adsorbed carbonaceous species could partially diffuse into the glass forming a layer of near-surface dissolved carbonates during heating. Such an effect seems reasonable as Figure 6 indicates a large amount of carbonaceous surface species even during progressive heating. In this way, desorption of these species can be accompanied by simultaneous inward diffusion. Once desorption is complete, the dissolved carbonaceous species may provide a further source of $\mathrm{CO}_{2}$ degassing. Such a possibility might be indicated by Figure 5 in as much as the onset of the degassing activity at $\approx 650-800^{\circ} \mathrm{C}$ nicely correlates with glass transition temperature $\left(T_{\mathrm{g}}\right)$. This latter mechanism is most likely responsible for foaming as it is obviously retarded by sintering. Similar VHE degassing patterns could be attributed to the diffusive release of bulk water (Müller et al., 2005). $\mathrm{CO}_{2}$ dissolution in oxide glasses was comprehensively studied by Brooker et al. (2001) who detected $\mathrm{CO}_{3}^{2-}$ like species in different local environments, albeit at higher pressure and temperature (0.2-2.7 GPa, $1175-1700^{\circ} \mathrm{C}$ ) and not for boron-containing glasses. $\mathrm{CO}_{2}$ solubility of 0.11 and $0.28 \mathrm{wt} \%$ was reported for natural rhyolytic melts at $1100^{\circ} \mathrm{C}$ for 200 and $500 \mathrm{MPa}$, respectively (Tamic et al., 2001). Although much lower solubility should be expected for 1 bar, increased local pressure can be expected during sintering and healing of the mechanically damaged near-surface region of milled glass powders.

\section{Foaming Mitigation Strategies}

As shown above, encapsulated gas can contribute to the foaming of coarse glass powders. In this case, vacuum sintering seems to be the only foaming mitigation strategy. On the other hand, gases with better mobility could help to enhance diffusive degassing from closed porosity below the onset of foaming.

As clearly shown in the present study and known from common experience, gases trapped on the powder surface can essentially contribute to foaming. Hence, the use of coarser glass particles is the most obvious and probably the most frequently applied strategy in reducing sinter foaming.

Beyond this, however, the present study (sintering at $\approx 700$ $800^{\circ} \mathrm{C}$ ) indicates that foaming is dominated by carbon gases, even when organic aids have not been used in powder processing, and that foaming can be affected by the milling atmosphere, milling aids, and powder storage. These observations can be reasonably explained assuming that gas uptake occurs at the freshly fractured and highly damaged glass powder surface as a relaxation mechanism and that carbonaceous species are preferentially adsorbed as a result of adsorption-desorption phenomena during milling or later storage. 
In this sense, further foaming mitigation strategies could be based on minimizing the possible uptake of ambient $\mathrm{CO}_{2}$ during powder processing. Among these strategies, powder processing in a controlled atmosphere or vacuum seems to be the most obvious but probably most expensive method. Alternatively, less $\mathrm{CO}_{2}$ uptake can be achieved by means of blocking active (i.e., the most basic) glass surface sites, which are most likely related to $\mathrm{BaO}$.

The significant decrease of foaming activity attained by water milling presented in Figure 7 indicates that this blocking can be made with water. Figure 5 shows that water does not contribute much to foaming, although it is the most prominent degassing species below the onset of sintering. This advantage probably reflects its better diffusivity. It should be noted, however, that this strategy relies on sufficiently high sintering temperatures. For lower sintering temperatures, water and even less stable species could also contribute to foaming. Additional $\mathrm{BaCO}_{3}$ formation during water milling as a result of aqueous dissolution of $\mathrm{Ba}$ from the glass surface and $\mathrm{CO}_{2}$ from the ambient atmosphere does not seem very likely since a $\mathrm{pH}$ value $>12$ is required for $\mathrm{BaCO}_{3}$ formation at 1 bar (Brookins, 1988) and $\mathrm{pH}<11$ was measured for milling in water in the present study.

Alternatively, foaming was substantially reduced by milling in $10 \mathrm{wt} \% \mathrm{HCl}$ (Figure 7). The decreased shrinkage rate and the simultaneously increased foaming onset temperature indicate increased glass viscosity, at least near to the powder surface. Such phenomenon could be caused by Ba dissolution from the glass surface. It is reasonable to assume that this effect would allow the formation of $\mathrm{BaCl}_{2}$, which is thermally stable up to $963^{\circ} \mathrm{C}$ (melting point) (Merck, 2015). In this sense, Ba dissolution from the glass surface and the formation of thermally stable Ba salts may provide another strategy for blocking active $\mathrm{CO}_{2}$ adsorption sites. In acidic aqueous solutions, $\mathrm{CO}_{2}$ solubility is also very limited (Acker et al., 1999).

Another foaming mitigation strategy could be utilizing increased sintering temperatures. This is due to the fact that foaming intensity is controlled by the temperature relationships between densification $\left(T_{\mathrm{S}}\right)$, decomposition of foaming species $\left(T_{\mathrm{D}}\right)$, and crystallization $\left(T_{\mathrm{C}}\right)$. Most pronounced foaming is expected for $T_{\mathrm{S}}<T_{\mathrm{D}}<T_{\mathrm{C}}$. For $T_{\mathrm{D}} \ll T_{\mathrm{S}}$ surface-adsorbed foaming agents largely decompose and escape via open pores. For $T_{\mathrm{D}} \approx T_{\mathrm{S}}$, this degassing process is retarded by closing porosity, which later yields gas bubble formation and foaming. Due to this general relationship, foaming probability seems to increase with decreasing sintering temperature as even less stable surface-adsorbed species (e.g., water or less stable carbonaceous species as indicated by Figure 5) may contribute to foaming. On the other hand, a higher sintering temperature can, for example, affect redox equilibria of the glass melt, increase oxygen mobility, and could cause oxygen degassing as a new foaming source. For most practical cases, however, a substantial change of glass transition temperature does not seem to be an applicable foaming mitigation strategy.

For a given glass, however, foaming of coarse powders is expected to be less intense not only due to the fact that a less specific surface will adsorb less foaming species as discussed above but also due to the more complete degassing, which can occur until porosity is closed. On the other hand, sintering is controlled by the effective viscosity of powder compacts. Hence, dispersed rigid particles can also decrease the shrinkage rate (Müller et al., 2007; Müller and Reinsch, 2012) and therefore provide more complete surface desorption. In a similar sense, glasses with a less temperature-dependent viscosity, causing a broader temperature range of sintering, should be less prone to foaming.

For $T_{\mathrm{D}}>T_{\mathrm{C}}$, foaming can be retarded by the presence of crystals, which hinder gas bubble coalescence and growth due to the increased effective viscosity of the crystal bearing melt. If full densification is not reached $\left(T_{\mathrm{C}} \approx T_{\mathrm{S}}\right)$, the remaining open porosity will allow full degassing without foaming even when $T_{\mathrm{S}}<T_{\mathrm{D}}$

However, our final conclusions on how to mitigate sinter foaming, beyond the rather speculative discussion presented here, require much deeper understanding of the potential foaming mechanism and may largely depend on given experimental or processing conditions.

\section{CONCLUSION}

Sintering and foaming of barium silicate glass powder compacts were studied for different milling times and atmospheres. Foaming was strongly promoted by progressive milling and was affected by the milling atmosphere where foaming activity increased in the order $\mathrm{Ar} \approx \mathrm{N}_{2}<$ air $<\mathrm{CO}_{2}$. For moderately milled glass powders, subsequent storage in air could also promote foaming. Degassing studies revealed that foaming is mainly driven by $\mathrm{CO}_{2}$ even for powders milled in $\mathrm{Ar}$ and $\mathrm{N}_{2}$. Only traces of these species were detected during bubble bursting of compacts for which glass powder milling was performed within these atmospheres. This observation, together with respective estimation of the possible amount of gas encapsulated within the closing porosity during densification, suggests that an encapsulated milling atmosphere does not dominate foaming. Instead, a potentially large effect on foaming of stable surface-adsorbed carbonaceous species was indicated by enhanced $\mathrm{CO}_{2}$ degassing during foaming. In this sense, milling in water and weak $\mathrm{HCl}$ acid could substantially reduce foaming.

\section{AUTHOR CONTRIBUTIONS}

RM: acquisition and design of the work, data interpretation, literature review, partial manuscript draft and revising, and final approval.SR: conception of experimental work, thermo-analytical measurements and data interpretation, literature review, partial manuscript draft, and final approval. BA-B: conception of experimental work, other experimental work, data analysis, literature review, partial manuscript draft, and final approval. All authors agree to be accountable for all aspects of the work.

\section{ACKNOWLEDGMENTS}

We gratefully acknowledge experimental support by our colleagues M. Gaber (vacuum hot extraction), R. Sojref (glass powder preparation and characterization), I. Feldmann (SEM), and D. Nicolaides (XRD). We finally acknowledge financial support by Erasmus Lifelong Learning Programs for BA-B (MINISTERIO DE EDUCACIÓN, CULTURA Y DEPORTE \# 11015347). 


\section{REFERENCES}

Acker, K., Barnes, I., Becker, K.-H., Crutzen, P. J., Hüttl, R., and Kalaß, D. (1999). Atmospheric Environmental Research: Critical Decisions between Technological Progress and Preservation of Nature, 1st Edn. Heidelberg, Germany: Springer, 186.

Agea Blanco, B., Blaess, C., Reinsch, S., Brauer, D., and Müller, R. (2015). Sintering and foaming of barium and calcium silicate glass powders. Addition. Conf. 2015, 000031-000037. doi:10.4071/CICMT-TA21

Antonini, J. F., and Hochstra, G. (1972). Surface states of pristine silica surfaces: II. UHV studies of the $\mathrm{CO}_{2}$ adsorption-desorption phenomena. Surf. Sci. 32, 665-686. doi:10.1016/0039-6028(72)90193-8

Baker, G. J., Greaves, G. N., Surman, M., and Oversluizen, M. (1995). An oxygen XAFS study of sodium disilicate glass surfaces. Nucl. Instrum. Methods Phys. Res. Sect. B-Beam Interact. Mat. Atoms 97, 375-382. doi:10.1016/0168-583X(95)00332-0

Bhushan, B. (2013). Solid Surface Characterization. Introduction to Tribology, 2nd Edn. West Sussex: John Wiley \& Sons.

Brooker, R. A., Kohn, S. C., Holloway, J. R., and McMillan, P. F. (2001). Structural controls on the solubility of $\mathrm{CO}_{2}$ in silicate melts: part II: IR characteristics of carbonate groups in silicate glasses. Chem. Geol. 174, 241-254. doi:10.1016/ S0009-2541(00)00318-1

Brookins, G. D. (1988). Eh-pH Diagrams for Geochemistry, 1st Edn. Berlin, Heidelberg: Springer-Verlag.

Cerruti, M., and Morterra, C. (2004). Carbonate formation on bioactive glasses. Langmuir 20, 6382-6388. doi:10.1021/la049723c

Doremus, R. H. (1973). Glass Science. New York, USA: John Wiley \& Sons, 133.

Dunken, H. H. (1981). "Chemische Reaktionen an Glasoberflächen," in Physikalische Chemie der Glasoberfläche (Leipzig: VEB Deutscher Verlag für Grundstoffindustrie), 262-338.

Epling, W. S., Peden, C. H. F., and Szanyi, J. (2008). Carbonate formation and stability on a $\mathrm{Pt} / \mathrm{BaO} / \gamma-\mathrm{Al}_{2} \mathrm{O}_{3} \mathrm{NOx}$ storage/reduction catalyst. J. Phys. Chem. $\mathrm{C}$ 112, 10952-10959. doi:10.1021/jp712180q

Eremenko, G. O., Larichev, M. N., and Leypunsky, I. O. (1991). “Thermal desorption mass-spectrometric (TDMS) analysis of the carbon dioxide desorption from the glass fiber surface," in MICC 90, ed. I.N.e.a. Fridlyander (Moscow: Elsevier Science Publishers Ltd.).

Fergus, J. W. (2005). Sealants for solid oxide fuel cells. J. Power Sources 147, 46-57. doi:10.1016/j.jpowsour.2005.05.002

Fernandes, H. R., and Ferreira, J. M. F. (2007). Recycling of chromium-rich leather ashes in porcelain tiles production. J. Eur. Ceram. Soc. 27, 4657-4663. doi:10.1016/j.jeurceramsoc.2007.03.037

FRITSCH GmbH. (1987). Operator's Manual "pulverisette 5". Idar-Oberstein: Fritsch $\mathrm{GmbH}$.

FRITSCH GmbH. (1995). Operator's Manual “pulverisette 7" Version 1. IdarOberstein: Fritsch GmbH

German, R. M. (1996). Sintering Theory and Practice. New York, Chichester, Brisbane, Toronto, Singapore: John Wiley \& Sons, Inc.

Gross, S. M., Koppitz, T., Remmel, J., and Reisgen, U. (2005). "Glass-ceramic materials of the system $\mathrm{BaO}-\mathrm{CaO}-\mathrm{SiO}_{2}$ as sealants for SOFC applications," in International Conference on Advanced Ceramics and Composites Ceramic Engineering and Science Proceedings, eds N. Bansal, D. Zhu, and W. M. Kriven (Cocoa Beach, FL), 239-245.

Hwang, G. H., Jeon, H. J., and Kim, Y. S. (2002). Physical properties of barrier ribs of plasma display panels: I, formation of pores during sintering of lead borosilicate glass frits. J. Am. Ceram. Soc. 85, 2956-2960. doi:10.1111/j.1151-2916. 2002.tb00562.x

Imanaka, Y. (2005). Multilayered Low Temperature Cofired Ceramics (LTCC) Technology. New York: Springer.

Kalinkin, A. M., and Kalinkina, E. V. (2010). The mechanosorption of carbon dioxide by magnesium, calcium, and strontium metasilicates. Russ. J. Phys. Chem. A 84, 1585-1591. doi:10.1134/S0036024410090256

Kerafol. (2010). Glass solder powder type K01 (Product-ID 6.FC0700.DL.00000) Supplied by Kerafol Keramische Folien GmbH Eschenbach Germany.

Kim, B.-S., Lim, E.-S., Lee, J.-H., and Kim, J.-J. (2007). Effect of $\mathrm{Bi}_{2} \mathrm{O}_{3}$ content on sintering and crystallization behavior of low-temperature firing $\mathrm{Bi}_{2} \mathrm{O}_{3}-\mathrm{B}_{2} \mathrm{O}_{3}-\mathrm{SiO}_{2}$ glasses. J. Eur. Ceram. Soc. 27, 819-824. doi:10.1016/j.jeurceramsoc.2006.04.013

Lara, C., Pascual, M. J., Prado, M. O., and Durán, A. (2004). Sintering of glasses in the system $\mathrm{RO}-\mathrm{Al}_{2} \mathrm{O}_{3}-\mathrm{BaO}-\mathrm{SiO}_{2}(\mathrm{R}=\mathrm{Ca}, \mathrm{Mg}, \mathrm{Zn})$ studied by hot-stage microscopy. Solid State Ionics 170, 201-208. doi:10.1016/j.ssi.2004.03.009
Leonelli, C., Bondioli, F., Veronesi, P., Romagnoli, M., Manfredini, T., Pellacani, G. C., et al. (2001). Enhancing the mechanical properties of porcelain stoneware tiles: a microstructural approach. J. Eur. Ceram. Soc. 21, 785-793. doi:10.1016/ S0955-2219(00)00266-1

Lim, E. S., Kim, B.-S., Lee, J.-H., and Kim, J.-J. (2006). Effect of $\mathrm{BaO}$ content on the sintering and physical properties of $\mathrm{BaO}-\mathrm{B}_{2} \mathrm{O}_{3}-\mathrm{SiO}_{2}$ glasses. J. Non-Cryst. Solids 352, 821-826. doi:10.1016/j.jnoncrysol.2006.01.021

Liptay, G. (1976). Atlas of Thermoanalytical Curves, Vol. 5. Budapest, Hungary: Akademiai Kiado.

Lucchini, E., Meriani, S., and Slokar, G. (1983). Sintering of glass bonded ceramic barium hexaferrite magnetic powders. J. Sci. Mater. 18, 1331-1334. doi:10.1007/ BF01111950

Merck. (2015). Sicherheitsdatenblatt Version 10.13 für Bariumchlorid 99.995 Suprapur ${ }^{\circledR}$, CAS-Nr. 10361-37-2. Available at: www.merckgroup.com

Morterra, C., Zecchina, A., Coluccia, S., and Chiorino, A. (1977). I.R. spectroscopic study of $\mathrm{CO}_{2}$ adsorption onto $\eta-\mathrm{Al}_{2} \mathrm{O}_{3}$. J. Chem. Soc. Faraday Trans. I 73, 1544-1560. doi:10.1039/f19777301544

Müller, R. (1994). On the kinetics of sintering and crystallization of glass powders. Glastech. Ber-Glass Sci. Technol. 67C, 93-98.

Müller, R., Eberstein, M., Reinsch, S., Schiller, W. A., Deubener, J., and Thiel, A. (2007). Effect of rigid inclusions on sintering of low temperature co-fired ceramics. Phys. Chem. Glass. Eur. J. Glass Sci. Technol. B 48, 259-266.

Müller, R., Meszaros, R., Peplinski, B., Reinsch, S., Eberstein, M., Schiller, W. A., et al. (2009). Dissolution of alumina, sintering, and crystallization in glass ceramic composites for LTCC. J. Am. Ceram. Soc. 92, 1703-1708. doi:10.1111/j.1551-2916.2009.03089.x

Müller, R., Gottschling, P., and Gaber, M. (2005). Water concentration and diffusivity in silicates obtained by vacuum extraction. Glass Sci. Technol. 78, 76-89.

Müller, R., and Reinsch, S. (2012). "Viscous phase silicate processing," in Processing Approaches for Ceramics and Composites, eds N.Bansal and A. R.Boccaccini (Hoboken, New Jersey, USA: John Wiley \& Sons), 75-144.

Pascual, M. J., and Duran, A. (2003). Sintering with concurrent crystallisation of a borosilicate glass. Phys. Chem. Glasses 44, 409-415.

Prado, M. O., Fredericci, C., and Zanotto, E. D. (2003a). Non-isothermal sintering with concurrent crystallization of polydispersed soda-lime-silica glass beads. J. Non-Cryst. Solids 331, 157-167. doi:10.1016/j.jnoncrysol.2003. 08.076

Prado, M. O., Zanotto, E. D., and Fredericci, C. (2003b). Sintering polydispersed spherical glass particles. J. Mater. Res. 18, 1347-1354. doi:10.1557/ JMR.2003.0185

Prado, M. O., Nascimento, M. L. F., and Zanotto, E. D. (2008). On the sinterability of crystallizing glass powders. J. Non-Cryst. Solids 354, 4589-4597. doi:10.1016/j. jnoncrysol.2008.06.006

Prado, M. O., and Zanotto, E. D. (2002). Glass sintering with concurrent crystallization. Comptes Rendus Chimie 5, 773-786. doi:10.1016/S1631-0748(02) 01447-9

Rabinovich, E. M. (1985). Preparation of glass by sintering. J. Sci. Mater. 20, 4259-4297. doi:10.1007/BF00559317

Schiller, W. A., Müller, R., Eberstein, M., Reinsch, S., and Rabe, T. (2008). Sintering of LTCC. cfi/Berichte der DKG 85, 12-17.

Sieber, H. (1980). Mathematische Tafeln, 2nd Edn. Stuttgart, Germany: Ernst Klett Verlag.

Tamic, N., Behrens, H., and Holtz, F. (2001). The solubility of $\mathrm{H}_{2} \mathrm{O}$ and $\mathrm{CO}_{2}$ in rhyolitic melts in equilibrium with a mixed $\mathrm{CO}_{2}-\mathrm{H}_{2} \mathrm{O}$ fluid phase. Chem. Geol. 174, 333-347. doi:10.1016/S0009-2541(00)00324-7

Winkel, A., Meszaros, R., Reinsch, S., Müller, R., Travitzsky, N., Frey, T., et al. (2012). Sintering of 3D-printed glass/hap composites. J. Am. Ceram. Soc. 95, 3387-3393. doi:10.1111/j.1551-2916.2012.05368.x

Conflict of Interest Statement: The authors declare that the research was conducted in the absence of any commercial or financial relationships that could be construed as a potential conflict of interest.

Copyright (c) 2016 Agea-Blanco, Reinsch and Müller. This is an open-access article distributed under the terms of the Creative Commons Attribution License (CC BY). The use, distribution or reproduction in other forums is permitted, provided the original author(s) or licensor are credited and that the original publication in this journal is cited, in accordance with accepted academic practice. No use, distribution or reproduction is permitted which does not comply with these terms. 